\title{
Introduction: systematicity, the nature of science?
}

\author{
Karim Bschir ${ }^{1}$. Simon Lohse ${ }^{2}$ - Hasok Chang ${ }^{3}$
}

Received: 16 October 2017 / Accepted: 4 January 2018 / Published online: 1 February 2018

(C) Springer Science+Business Media B.V., part of Springer Nature 2018

This special issue provides a forum for the discussion of Paul Hoyningen-Huene's book Systematicity: The Nature of Science (2013) and the approach it introduces. Hoyningen-Huene's book marks the first attempt in many years to provide a comprehensive philosophical account of science at the highest possible level of generality and abstraction. It raises one central question: what is the nature of science? Before turning to Hoyningen-Huene's own answer and the contributions in this collection, let us put the question into context.

Many scholars working in the philosophy of science are inclined to declare the question about the nature of science as futile. The question makes a problematic presumption, they argue, namely that there must be something that all practices subsumed under the term "science" have in common. But a close look at modern science just reveals an overwhelming diversity of experimental and computational methods, theoretical approaches, and epistemic standards that are applied in a huge variety of disciplinary traditions - especially if we follow Hoyingen-Huene and take the broad meaning of "science", as in the German term Wissenschaft. It would seem that fields

$凶 \quad$ Karim Bschir

bschir@phil.gess.ethz.ch

Simon Lohse

lohse@ww.uni-hannover.de

Hasok Chang

hc372@cam.ac.uk

1 Department of Humanities, Social and Political Sciences, Swiss Federal Institute of Technology Zurich, Zurich, Switzerland

2 CELLS-Centre for Ethics and Law in the Life Sciences, and Centre for Ethics and Philosophy of Science (Institute of Philosophy), Leibniz Universität Hannover, Hannover, Germany

3 Department of History and Philosophy of Science, University of Cambridge, Cambridge, UK 
like Eastern European history and antibiotic resistance research, for instance, have very little in common; any features that they happen to share, like the fact that they are both established and conducted in academic institutions, appear to be of little philosophical interest, let alone revealing anything essential or significant about science in general. After all, investigating the "essence" or "nature" of anything has been shown to be an ineffective enterprise in a great number of cases. From this perspective, trying to answer the question "What is the nature of science?" appears to be a fruitless, or even misguided, philosophical project.

As a matter of fact, philosophers of science have rarely tackled this question in recent decades. ${ }^{1}$ Instead, there has been an emphasis on the disunity of science (see for instance Dupré 1993; Galison and Stump 1996; Cartwright 1999). And almost like the sciences themselves, philosophy of science has witnessed a strong tendency towards ever-greater specialization. The philosophies of the special sciences have diversified to the extent that it has become difficult to recognize many points of contact between them.

Despite the good reasons that exist for philosophers of science to focus their research on specific scientific disciplines or to tackle highly specialized ontological, epistemological and methodological problems, we, the guest editors of this special issue, are driven by the belief that raising the question about the nature of science in the most general sense is still relevant and philosophically legitimate. There are four main reasons for thinking that there should be room for a general philosophy of science and its central question about the nature of science:

(1) The question is relevant for philosophy in a broad sense, as one of the main goals of modern philosophy has been to act as an intermediary between what Sellars (1962) called the "manifest image" and the "scientific image" of the world. How should we reconcile recent findings in neuroscience with our common sense concept of free will and rational action? Is it possible to integrate the concepts of modern physics with our everyday understanding of notions like space, time, and causality? To what extent is our everyday understanding of personal success compatible with insights of empirical educational research stressing latent environmental determinants of success? How should we modify our folk psychology in light of recent findings in astrology and voodoo healing? If you were slightly confused after reading the third question, perhaps you are not entirely sure whether educational research really contributes to the "scientific image" of the world. If you flinched after reading the fourth question, you probably share the common conviction that astrology and voodoo metaphysics are not part of the scientific image of the world. But what is it that makes neuroscience and physics a legitimate contributor to the scientific image, but perhaps not educational research, and certainly not astrology and voodoo healing? In other words, what is it that distinguishes science from other forms of epistemic engagement with reality? In many areas of philosophy answers to these kinds of questions seem to be presupposed implicitly. We think, however, that it is important to investigate carefully the grounds for each answer and the related concept of the

\footnotetext{
1 Of course, there are a handful of notable exceptions to the widespread skepticism against a general philosophy of science. See for instance Psillos (2012).
} 
"scientific image". In our opinion, grounding various discourses in philosophy in a broad sense is a key task for a general philosophy of science. ${ }^{2}$

(2) As mentioned above, philosophy of science has branched into a large number of sub-fields in the philosophy of the special sciences in the last decades. There exist not only philosophies of the natural sciences (physics, chemistry, biology etc.) and of the social sciences (sociology, ethnography, economics etc.), but many more philosophies of the special sciences, including the humanities (historiography, literary studies, jurisprudence etc.), the formal sciences (mathematics, theoretical informatics, statistics etc.) and even some philosophies of interdisciplinary sciences (e.g. climate science and cognitive science). We certainly do not believe that all these sub-disciplines should be re-integrated in some kind of all-encompassing general philosophy of science. However, the philosophies of the special sciences do need some kind of common core linking together at least some of their aspects. Without such a background or some dialogue concerning the nature of science, it remains unclear why the "special sciences" should be considered different instances of a coherent category of "science" at all. If one is not ready to accept the disparity between the different sub-fields of philosophy of science as a brute fact that needs no explanation, addressing the question about the nature of science from a general perspective becomes unavoidable.

(3) A similar argument holds for science itself. As is well known, modern science has specialized into a vast number of heterogeneous sub-disciplines. Many observers of science have been quite critical of this development, lamenting a lack of integration of scientific knowledge and "professional atomization" (Wilson 1999: p. 42), which may seem even more problematic in light of the grand challenges of the twenty-first century such as climate change and food security issues, to name just two examples. We do not believe that philosophy of science can or should unite the sciences into some kind of grand system of knowledge. We do believe, however, that philosophy of science can and should help to illuminate connections between different scientific disciplines, thereby (a) articulating a sense of unity permeating the scientific enterprise as a whole, (b) justifying the common and unified institutional organization of various disciplines, (c) promoting interdisciplinary discourse and understanding, and, last but not least, (d) supporting science education, which needs to presuppose some idea of the scientific enterprise after all.

(4) The final reason for the importance of the question about the nature of science is linked to its public role. Trust in science as a provider of rational guidance for policy-making and an unbiased source of facts for society has been eroding in certain contexts in recent years-with Turkish schools dropping the theory of evolution from the curriculum and the prevalence of anti-science politics in the US as particular low points (see Kingsley (2017) and Nuccitelli (2017) for illustrative purposes, and Mooney (2005) for a longer-term view). The credibility of science has been damaged due to external factors, such as doubt-mongering by industry

\footnotetext{
2 In a plenary address at the meeting of the European Philosophy of Science Association in September 2017, Philip Kitcher also advocated the idea that philosophy of science can be of great value for philosophy more broadly, in particular for ethics and metaphysics.
} 
lobbyists or anti-science propaganda by politicians (see Oreskes and Conway 2010), as well as internal issues such as data manipulation or fraud by prominent scientists (see Judson 2004). Hence, the debate concerning the justification of the (alleged) special status of science as a provider of objective knowledge is gaining renewed urgency, clearly recognized by sociologists of science such as Sergio Sismondo (2017) — an urgency that philosophers of science should not ignore.

\section{Some history}

In order to understand how Hoyningen-Huene's approach relates to previous attempts that have been made to clarify the special character of science and scientific knowledge, we want to give a brief overview of the relevant developments in the philosophy of science in the twentieth century. Hoyningen-Huene himself is very conscious about how his view compares and connects with existing views, and we want to provide some background here that will help situate Hoyningen-Huene's contribution historically. The material in this section will mostly be common knowledge to well-informed philosophers of science, but we hope it will be helpful to various other readers.

At the risk of oversimplification, we find it instructive to distinguish three major phases in the history of twentieth-century philosophy of science (including the beginning of the twenty-first century). The first of these phases was dominated by the quest for a unified image of science. In the second phase, science is depicted as a contingent and heterogeneous enterprise, while in the third (ongoing) phase science is characterized by a complex mosaic of disciplinary diversity. We will attempt to highlight aspects of the developments that are particularly relevant to the positioning of Hoyningen-Huene's work.

\section{(I) Logical empiricism and critical rationalism: the unity of science}

Logical empiricism dominated the first phase, which roughly lasted from the early decades of the twentieth century into the $1950 \mathrm{~s}^{3}{ }^{3}$ The main programmatic goal of the logical empiricists was to combine the empiricist philosophical traditions of the eighteenth and nineteenth century with the recently developed tools of formal logic in order to provide a new and stronger epistemological foundation for modern science. All sciences should become unified through one single method, and that method consisted in the application of the tools of logical analysis to the material given in immediate experience (Neurath et al. 1973, pp. 306-307).

The image of science that emerged out of this type of inquiry was dominated by three main programmatic features: (1) An unconditional commitment to empirical testability: any meaningful and legitimate scientific claim has to be verifiable by empirical data. Theories that make untestable claims about empirical reality must be rejected as metaphysical and unscientific. (2) A rejection of the synthetic a priori: all knowledge about empirical reality has to be derived inductively from empirical data. Experience was not only considered as the only legitimate authority for the verification of a the-

\footnotetext{
3 Following Richardson and Uebel (2007), we are using the term "logical empiricism" as synonymous to "logical positivism" or "neo-positivism".
} 
ory, but also as the only legitimate source of scientific knowledge. (3) An ideal of a unified science: empirical testability and logical analysis provide the methodological foundation not only for the natural sciences, but likewise also for the social sciences.

A major obstacle for the logical empiricists was the problem of finding a workable verificationist criterion of meaning. For one thing, the full logical reduction of theoretical statements to purely observational statements turned out to be more difficult than expected (Carnap 1936). For another, despite the empiricist's artful attempts to solve the problem of induction, the complete verification of general statements by means of inductive logic turned out to be a difficult task (Reichenbach 1940; Creed 1940). The logical empiricists finally had to accept the fact that science contained non-reducible, experience-transcending statements that could neither be reduced to observational statements nor be fully verified by use of inductive methods, and thus could not be considered cognitively significant in the strict sense by their own reckoning. In light of these serious problems, Carl Hempel suggested a shift away from a strictly positivist program towards an analysis of the methodology of empirical science and a focus on topics like explanation, reduction, theory and simplicity (Hempel 1950, 1951).

Another attempt at liberating empiricism from the troubling consequences it had run into by its commitment to an inductive methodology was famously suggested by Karl Popper in his Logic of Scientific Discovery (1935, first Englisch edition 1959). Popper remained fully committed to the basic principles of empiricism and to the empirical testability of scientific claims. However, due to the logical asymmetry between verification and falsification, scientists should try to falsify theories instead of verifying them. Despite all of its differences from the logical empiricist program, Popper's approach, often dubbed "critical rationalism", likewise drew a picture of science that had the problem of method at its focal point. To do philosophy of science still meant thinking about a unified scientific methodology.

One of the greatest shortcomings of both philosophies was that they were prescriptive while being quite detached from actual scientific practice. They conveyed a theory of how science ought to proceed that was often at odds with how successful scientists actually went about their endeavors and how major scientific progress was achieved. Whenever such normative philosophies of science were exposed to the actual history of science, their unrealistic nature became apparent. But it took quite some time before the philosophical community came to accept the importance of history for the philosophy of science.

\section{(II) The dawn of modern HPS: scientific heterogeneity}

Thomas Kuhn's landmark Structure of Scientific Revolutions (1962) is considered as one of the most important works in modern philosophy of science. Referring to the works of Ludwik Fleck and Norwood Russell Hanson, and drawing on his own extensive expertise as a historian of science, Kuhn came to the conclusion that the philosophy of science needed to overcome the influence of a simplistic account of the history of science. The actual dynamics of scientific knowledge was much more intricate and discontinuous than either logical empiricism or critical rationalism had suggested.

Although Structure was originally commissioned as part of the logical empiricist Encyclopedia of Unified Science, Kuhn's claims did not resonate well within the philo- 
sophical community at the time. In fact, Kuhn was not taken very seriously among philosophers. The 1967 edition of Edwards' Encyclopedia of Philosophy does not even mention Kuhn's book. Paul Feyerabend helped to direct the attention of philosophers to Kuhn's ideas. Feyerabend had already acquired a decent reputation as a philosopher in the early 1960s. His 1962 article "Explanation, Reduction, and Empiricism" provided a strong criticism of logical empiricism and critical rationalism, and like Kuhn, Feyerabend also used the controversial concept of incommensurability to characterize the conceptual ruptures that we find in the development of science.

Logical empiricists and critical rationalists both tended to oppose Kuhn's and Feyerabend's ideas. However, some took up the challenge and engaged in the debate. Imre Lakatos' "Criticism and the Methodology of Scientific Research Programmes" (1968) may be seen as a dialectical attempt to integrate the novel ideas of Kuhn, Feyerabend and others into a sophisticated version of critical rationalism. Despite Lakatos's own strong normative bent, philosophers' attempts to accommodate Kuhnian insights tended to lead to less normative discussions in the field with a focus on the heterogeneity of different episodes of science, the dynamics of scientific change, and the importance of history of science for the philosophy of science. It was a rebirth of integrated history and philosophy of science, or HPS for short, which had in fact been pioneered in the late nineteenth century by the likes of Ernst Mach and Pierre Duhem, and William Whewell and Auguste Comte earlier. The fundamental insight of HPS consists in the claim that science is a deeply historical process and that its objectivity and the legitimacy of its claims can neither be derived from the empirically given nor from some ahistorical rational or transcendental principles. As such, the historical turn in the philosophy of science poses a challenge to empiricist and critical rationalist accounts of science alike.

Many of the debates initiated by Kuhn, Feyerabend, Lakatos, and their contemporaries including Norwood Russell Hanson, Mary Hesse and Stephen Toulmin, are still continuing today. In particular the issue of scientific realism and the controversy about the rationality of theory change in science had a long-lasting impact. Feyerabend's infamous slogan "anything goes"- which was clearly intended as an ironical remark towards those who thought that science can be characterized by a single unified method-was often taken as a call to relativize epistemology and the epistemic status of scientific knowledge. Extreme relativists even suggested that there exist no general principles of rationality in science, and that science has no legitimate right to a higher status than other forms of human knowledge, because it was, like all forms of knowledge, the result of historical contingency and social construction. Others were more cautious with their conclusions. In any case, the historical turn in the philosophy of science made clear the need for a more sophisticated theory of science as a historically heterogeneous enterprise and of the dynamics and rationality of scientific belief-change than the one provided by logical empiricism or critical rationalism.

\section{(III) The new complexity}

The third phase of the development of the philosophy of science in the twentieth century is not defined by a single dominant idea or overarching project. Philosophy of science from the late 1970s on is, in contrast, best described as fragmented in two dimensions. First, as already mentioned, we observe a specialization into a large num- 
ber of sub-philosophies of the special sciences. Naturally, debates in these sub-fields are not focused on science as a whole but on their respective scientific fields. That does not mean that overarching considerations are completely absent. Critical debates concerning mechanisms, for instance, have relevance to neuroscience, the social sciences and the biomedical sciences, and philosophical investigations into the logic of narrative explanations are drawing from historiography, geology and paleontology. However, debates such as these are usually limited to a subset of the sciences. They do not address science in a general sense.

The second dimension of fragmentation manifests itself in a great number of heterogeneous approaches to philosophy of science. There is no single mainstream project in current philosophy of science. In fact, there are many equally important approaches to the philosophical investigation of science. To be sure, HPS is still a thriving field. Even for philosophers who are not committed to the project of integrated HPS, historical case studies are commonly used to shed new light on old debates, or to gather evidence in support of established positions such as the pessimistic meta-induction against scientific realism (Donovan et al. 1988; Lyons 2016).

The social epistemology of science, also a descendant of Kuhn's work (Barnes 1982), is another example. Beginning with the work of sociologists of scientific knowledge (e.g., Bloor 1976; Latour and Woolgar 1979) and feminist philosophers of science (e.g., Code 1981; Harding 1982; Harding and Hintikka 1983; Keller 1985), there has been a growing interest in the social dimension of science: To what extent are epistemic aspects of science constituted by social factors? How do collectives generate and accept scientific facts? Some authors in this tradition have been pursuing a critical project, bringing to light social biases and cultural factors which are interfering with scientific objectivity (similarly, those authors following Karl Marx and Karl Mannheim). Others have been eager to point out the more positive aspects of collective knowledge production in the sciences, e.g. the benefits of the division of cognitive labor (Kitcher 1990) and institutionalized norms of critical scrutiny in epistemic communities (Longino 1990). Heather Douglas (2000, 2007, 2009) has made an important contribution to the revival of the debate about the value-free ideal of science and the role of social, ethical and political values in science (see also Machamer and Wolters (2004), Kincaid et al. (2007), Wilholt (2009), Brown (2013) and Betz 2013. For earlier contributions to the debate see Rudner (1953), Frank (1954), Hempel (1965) and Kuhn (1977)).

The "philosophy of science in practice" is yet another prominent recent approach to the study of science. While philosophers of science before the 1980s were predominantly concerned with theories as final products of science, Ian Hacking, Nancy Cartwright and others began to promote a new focus on scientific practice (see Soler et al. 2014). This led to a visible rise in philosophical studies of experimental practices (Guala 2005), the material dimension of science (Ankeny and Leonelli 2016), classificatory activities in scientific practice (Kendig 2016) and data-handling processes in the life sciences (Leonelli 2016). Philosophers of scientific practice typically identify as naturalist philosophers whose methods are continuous with those of the sciences. As a consequence, methods from the arsenal of the social sciences have become more and more integrated into the philosophy of science, blurring the boundaries between philosophy of science and sociology of science (Wagenknecht et al. 2015). 
This snapshot of recent philosophy of science is not nearly complete. There are many more approaches: a number of scholars have sought to enrich philosophy of science, and science studies more generally, through a more serious attention to technology (e.g., Scharff and Dusek 2003, Pt. IV; Hannsson 2015); various philosophers attempt to integrate analytical metaphysics and philosophy of science (e.g. Hicks and Schaffer 2017); there is a subfield of philosophers who are rebooting the logical empiricist project, carrying forward Carnap's ideal of a formal philosophy of science (see Leitgeb 2011); and one of the authors of this introduction has argued that HPS can be seen as a continuation of science by other means (Chang 1999, 2004, ch. 6).

This complex state of the art advances a detailed, multilayered and pluralist mosaic of the sciences and of philosophy itself. Historical and contemporary case studies inform us about the epistemic details of scientific practice in the special sciences and lost paths of scientific discovery. Ontological investigations relating to different scientific fields remind us of the complexity of a "dappled" world (Cartwright 1999). And Bayesian philosophers of science are developing norms of rationality for theory change in the natural and the social sciences (Howson and Urbach 1989; Bovens and Hartmann 2003). However, no comprehensive and commonly acceptable image of science emerges from these endeavors. Apparently, the question about the nature of science has been dissolved in this new complexity.

\section{Hoyningen-Huene's systematicity theory}

Paul Hoyningen-Huene's book is a refreshing renewal of the attempt at drawing a general picture of science, and engaging with questions about the nature of science in general. Hoyningen-Huene's main thesis is rather straightforward: Scientific knowledge distinguishes itself from other forms of knowledge through a higher degree of systematicity. In order to account for the manifold ways in which systematicity presents itself in science, Hoyningen-Huene unfolds the concept of systematicity along nine dimensions. These are: descriptions, explanations, predictions, the defense of knowledge claims, critical discourse, epistemic connectedness, an ideal of completeness, knowledge generation, and the representation of knowledge. The first part of the book is dedicated to an in-depth discussion of these nine dimensions of systematicity. A scientific discipline need not necessarily be systematic in all of the nine dimensions. There are many fully legitimate fields of science, which do not systematically engage in prediction, but may be highly systematic with respect to others. The systematicity of a scientific discipline, as Hoyningen-Huene conceives it, is a relative feature that displays itself only in comparison to corresponding parts of everyday knowledge. In this sense, scientific taxonomies, for instance, are more systematic than systems of categorization found in everyday life, and that is precisely what marks their scientific character.

In the second part of the book, systematicity theory is compared to the accounts of Aristotle, Descartes, Kant, the logical empiricists, Popper, Kuhn, Feyerabend, and Rescher. All these philosophers made important contributions to our understanding of the nature of science, but, according to Hoyningen-Huene, gave only partial answers to the question "What is science?" Systematicity theory is supposed to be compatible with all the mentioned positions, but provides a more general account of the nature of 
science than its predecessors. They can thus be seen as "restricted versions of the idea of systematicity in nine dimensions" (Hoyningen-Huene 2013, p. 150).

In the third part, some consequences for scientific knowledge and our understanding of science in general are discussed; in particular, consequences concerning debates about the genesis and the dynamics of science, about the relationship between science and common sense, and about the demarcation problem.

The view of science that emerges from Hoyningen-Huene's account differs from earlier comparable projects in three significant ways. First, unlike attempts at the question about the nature of science in phase I and II of our brief history above, Hoyningen-Huene's approach is not restricted to the natural and the social sciences. It is his declared goal to understand and explicate the nature of science as generally as possible. This means that his analysis extends to the humanities, to the formal sciences and even to the theoretical parts of the arts. Thus, when Hoyningen-Huene speaks about "science" he uses the term in the broadest sense possible.

Second, Hoyningen-Huene does not try to answer the question "What is science?" by providing a set of ahistorical and discipline-independent criteria that would allow one to formulate the necessary and sufficient conditions under which any practice might legitimately be called "scientific". So the answer we may expect from HoyningenHuene will certainly not be a set of criteria that helps us to classify any given human practice under the label "scientific" or not, thereby capturing the essence of science. Instead, Hoyningen-Huene refers to Wittgenstein's concept of family resemblance, according to which the members of a certain class (for example, "games") do not necessarily have to share some essential property. Rather, the members of the class can be grouped into subclasses each of which will share some properties with some of the other subclasses. In the same vein, Hoyningen-Huene intends to approach the class of all sciences and the resemblances that exist among the individual members of that class. So, what he definitely does not provide is a definition of "science" in terms of necessary and sufficient conditions.

The third feature that distinguishes Hoyningen-Huene's project from others concerns the intended contrast-class when investigating the nature of science. Usually, when philosophers have considered the nature of science in a general way, they did so with the intent to demarcate science from what they called pseudo-science or metaphysics. The primary contrast that Hoyningen-Huene has in mind is the one between science as a specific form of knowledge and other forms of knowledge. In particular, he wants to capture scientific knowledge in contrast to everyday knowledge. Accordingly, Hoyningen-Huene's account will not provide a clear-cut criterion for the traditional demarcation problem as traditionally conceived, which tended to focus on how to distinguish real science from inferior and problematic practices. But the account certainly will have something to say about how that problem should be approached and what a potential solution should be offering.

Hoyningen-Huene's approach has two (closely related) key advantages that we would like to stress. First, the complexity and diversity of the scientific enterprise is taken seriously instead of reducing science to a small number of core disciplines that philosophers of science happen to like most (i.e. physics, biology, perhaps psychology, and a pinch of medicine and social science). Second, it works bottom-up by looking at a great number of different scientific subfields and only then conceptualizing the 
main elements of science as a whole. This is indeed an advantage of HoyningenHuene's approach, as it avoids certain forms of philosophy-of-science-imperialism, where every scientific discipline is squeezed into a narrow framework that has been derived from looking at only a small fragment of the scientific enterprise.

Naturally, an approach that is this inclusive and ambitious raises a number of critical questions as well; for example: (1) Systematicity theory aims at encompassing all the sciences including the natural sciences, the formal sciences, the social sciences and even the humanities. Does Hoyningen-Huene really succeed in integrating these very different disciplines in an all-encompassing and, at the same time, enlightening and non-trivial picture of science? (2) Hoyningen-Huene attempts to integrate the philosophies of science of his major predecessors (Descartes, Popper, Kuhn etc.) into systematicity theory. But is this attempt successful or does the author omit important features of their philosophical doctrines? (3) Systematicity theory focuses on scientific knowledge. Does that mean that it downplays scientific practice and sociological aspects of science that have been at the center of many cutting-edge debates in the philosophy of science in recent years? (4) In the last part of the book, Hoyningen-Huene outlines a diachronic approach to the traditional demarcation problem in philosophy of science that builds on differences in the development of science and pseudo-science respectively. Is this context-sensitive approach really capable of dealing with pseudoscientific challenges in the twenty-first century? Some of these questions and many more critical points will be addressed by the contributing authors of this special issue.

\section{Overview of the special issue}

The first contribution in this special issue, by Chrys Mantzavinos, is written in form of a dialogue between Paul Hoyningen-Huene and a student. The dialogue outlines the key aspect of systematicity theory and discusses several objections against it. In the last part, the student - who might be loosely based on the author of the dialogue - outlines an alternative theory of science, which is built around a specific concept of scientific rationality and the institutionalization of the possibility of criticism.

Sara Green examines the relationship between scientific knowledge and commonsense intuitions. She gives special attention to the cognitive aspects of learning and doing science, and asks whether common-sense intuitions facilitate or impede scientific reasoning. Her conclusion is that an adjusted version of systematicity theory in combination with insights from cognitive science could help clarify important organizational aspects of science.

Brad Wray argues that common-sense knowledge and scientific knowledge have to be considered as discontinuous in an important sense. Wray discusses some remarks to the contrary in Systematicity in order to defuse these and to corroborate the claim that Hoyningen-Huene indeed endorses what he calls the "discontinuity thesis". In the last part of the paper, Wray connects this conclusion with a discussion of the epistemic authority of scientists, which appears to be based on the systematicity of science.

Timothy Lyons examines systematicity theory in light of the scientific realism debate. He develops a sophisticated version of axiological realism, i.e. a realist hypothesis stating that science aims at a specific subclass of true claims, and argues that this 
hypothesis is not only compatible with systematicity theory but can actually explain and justify it on a deeper level.

Alexander Bird uses a case from the history of clinical medicine in the eighteenth century (James Lurin's investigations of smallpox) as a confirming instance for Hoyningen-Huene's thesis that systematicity is a distinctive feature of science. Bird's case illustrates how the processes required for producing the kind of knowledge sought by science need to be systematic in the ways described by Hoyningen-Huene.

Naomi Oreskes provides a critique of systematicity theory's approach to the demarcation problem, on the basis of a comprehensive analysis of three cases of what she calls "facsimile sciences": homeopathy, creationism, and climate-change denial. Oreskes examines the ways in which these fields successfully mimic scientific systematicity. Thus, although they are non-scientific according to the standards of most philosophers and scientists, they would have to count as scientific according to Hoyningen-Huene's theory, which suggests that aspects other than just systematicity are needed to demarcate science from facsimile sciences.

Paul Hoyningen-Huene has contributed a response article to the papers in this special issue, in which he replies to the critical points raised in the contributions. He also takes the opportunity to clarify certain aspects of systematicity theory, thereby taking the discussion about the nature of science further. Let us conclude this introduction by expressing our hope that this special issue will act as a catalyst for the advancement of the debate on the nature of science more broadly.

Acknowledgements We are grateful to Synthese's editors-in-chief for the opportunity to compile this special issue, and in particular to Gila Sher and Catarina Dutilh Novaes for the pleasant and professional collaboration. We would also like to thank all the anonymous reviewers who have provided constructive comments, and Thomas Reydon for his helpful advice during the whole process. Stefano Canali, Radin Dardashti, Martin Wasmer, and Jamie Shaw have provided constructive comments to this introduction. Last but not least, we thank the contributors to this special issue and - needless to say - Paul Hoyningen-Huene for his response article. Simon Lohse's work on this paper has been funded by R2N, Federal State of Lower Saxony (Germany). Karim Bschir is thankful for financial support by The Branco Weiss Fellowship Society in Science.

\section{References}

Ankeny, R. A., \& Leonelli, S. (2016). Repertoires: A post-Kuhnian perspective on scientific change and collaborative research. Studies in History and Philosophy of Science Part A, 60, 18-28.

Barnes, B. (1982). T. S. Kuhn and social science. London: Macmillan.

Betz, G. (2013). In defence of the value free ideal. European Journal for Philosophy of Science, 3(2), 207-220.

Bloor, D. (1976). Knowledge and social imagery. London: Routledge and Kegan Paul.

Bovens, L., \& Hartmann, S. (2003). Bayesian Epistemology. Oxford: Oxford University Press.

Brown, M. J. (2013). Values in science beyond underdetermination and inductive risk. Philosophy of Science, 80(5), 829-839.

Carnap, R. (1936). Testability and meaning. Philosophy of Science, 3(4), 419-471.

Cartwright, N. (1999). The dappled world: A study of the boundaries of science. Cambridge: Cambridge University Press.

Chang, H. (1999). History and philosophy of science as a continuation of science by other means. Science \& Education, 8(4), 413-425.

Chang, H. (2004). Inventing temperature: Measurement and scientific progress. New York: Oxford University Press. 
Code, L. B. (1981). Is the sex of the knower epistemologically significant? Metaphilosophy, 12(3-4), 267276.

Creed, I. P. (1940). The justification of the habit of induction. The Journal of Philosophy, 37(4), 85-97.

Donovan, A., Laudan, L., \& Laudan, R. (Eds.). (1988). Scrutinizing science: Empirical studies of scientific change. Dordrecht: Kluwer.

Douglas, H. (2000). Inductive risk and values in science. Philosophy of Science, 67(4), 559-579.

Douglas, H. (2007). Rejecting the ideal of value-free science. In J. Dupre, H. Kincaid, \& A. Wylie (Eds.), Value-free science: Ideal or illusion. Oxford: Oxford University Press.

Douglas, H. (2009). Science, policy, and the value-free ideal. Pittsburgh: University of Pittsburgh Press.

Dupré, J. (1993). The disorder of things: Metaphysical foundations of the disunity of science. Cambridge: Harvard University Press.

Feyerabend, P. (1962). Explanation, reduction, and empiricism. In H. Feigl \& G. Maxwell (Eds.), Scientific explanation, space, and time, Minnesota studies in the philosophy of science (Vol. 3). Minneapolis: University of Minnesota Press.

Frank, P. G. (1954). The variety of reasons for the acceptance of scientific theories. The Scientific Monthly, 79(3), 139-145.

Galison, P., \& Stump, D. J. (Eds.). (1996). The disunity of science: Boundaries, contexts, and power. Stanford: Stanford University Press.

Guala, F. (2005). The methodology of experimental economics. Cambridge: Cambridge University Press.

Hannsson, S. O. (Ed.). (2015). The role of technology in science: Philosophical perspectives. Dordrecht: Springer.

Harding, S. (1982). Is gender a variable in conceptions of rationality? A survey of issues. Dialectica, $36(2-3), 225-242$.

Harding, S., \& Hintikka, M. B. (1983). Discovering reality: Feminist perspectives on epistemology, metaphysics, methodology, and philosophy of science. Dordrecht: Reidel.

Hempel, C. G. (1950). Problems and changes in the empiricist criterion of meaning. Revue Internationale de Philosophie, 41, 41-63.

Hempel, C. G. (1951). The concept of cognitive significance: A reconsideration. Proceedings of the American Academy of Arts and Sciences, 80(1), 61-77.

Hempel, C. G. (Ed.). (1965). Science and human values. In Aspects of scientific explanation and other essays in the philosophy of science (pp. 81-96). New York: Free Press.

Hicks, M. T., \& Schaffer, J. (2017). Derivative properties in fundamental laws. The British Journal for the Philosophy of Science, 68, 411-450.

Howson, C., \& Urbach, P. (1989). Scientific reasoning: The Bayesian approach. La Salle, IL: Open Court. Hoyningen-Huene, P. (2013). Systematicity: The nature of science. Oxford: Oxford University Press.

Judson, H. F. (2004). The great betrayal: Fraud in science. Orlando: Harcourt.

Keller, E. F. (1985). Reflections on gender and science. New Haven: Yale University Press.

Kendig, C. (Ed.). (2016). Natural kinds and classification in scientific practice. London: Routledge.

Kincaid, H., Dupré, J., \& Wylie, A. (Eds.). (2007). Value-free science?: Ideals and illusions. Oxford: Oxford University Press.

Kingsley, P. (2017). Turkey drops evolution from curriculum, angering secularists. New York Times, 23 June 2017. https://www.nytimes.com/2017/06/23/world/europe/turkey-evolution-high-schoolcurriculum.html

Kitcher, P. (1990). The division of cognitive labor. The Journal of Philosophy, 87(1), 5-22.

Kuhn, T. S. (1962). The structure of scientific revolutions. Chicago: Chicago University Press.

Kuhn, T. S. (Ed.). (1977). Objectivity, value judgment, and theory choice. The essential tension (pp. 320339). Chicago: University of Chicago Press.

Lakatos, I. (1968). Criticism and the methodology of scientific research programmes. In In proceedings of the Aristotelian society (Vol. 69, pp. 149-186).

Latour, B., \& Woolgar, S. (1979). Laboratory life: The construction of scientific facts. Princeton, NJ: Princeton University Press.

Leitgeb, H. (2011). Logic in general philosophy of science: Old things and new things. Synthese, 179(2), 339-350.

Leonelli, S. (2016). Data-centric biology: A philosophical study. Chicago: University of Chicago Press.

Longino, H. E. (1990). Science as social knowledge: Values and objectivity in scientific inquiry. Princeton: Princeton University Press. 
Lyons, T. D. (2016). Scientific realism. In P. Humphreys (Ed.), The Oxford handbook of philosophy of science (pp. 564-584). New York: Oxford University Press.

Machamer, P., \& Wolters, G. (Eds.). (2004). Science, values, and objectivity. Pittsburgh: University of Pittsburgh Press.

Mooney, C. (2005). The Republican war on science. New York: Basic Books.

Neurath, O., Hahn, H., Carnap, R. (1973). The scientific conception of the world: The Vienna circle. In O. Neurath, Empiricism and sociology (pp. 299-318). Dordrecht: Riedel. German original: Wissenschaftliche Weltauffassung: Der Wiener Kreis (1929).

Nuccitelli, D. (2017). Trump has launched a blitzkrieg in the wars on science and Earth's climate. The Guardian. 28 March 2017. https://www.theguardian.com/environment/climate-consensus-97-percent/2017/mar/28/trump-has-launched-a-blitzkrieg-in-the-wars-on-science-and-earths-climate.

Oreskes, N., \& Conway, E. M. (2010). Merchants of doubt: How a handful of scientists obscured the truth on issues from tobacco smoke to global warming. New York: Bloomsbury Press.

Popper K. R. (1935). Logik der Forschung. Vienna: Julius Springer Verlag. First English edition: The logic of scientify discovery. London: Hutchinson, 1959.

Psillos, S. (2012). What is general philosophy of science? Journal for General Philosophy of Science, 43(1), 93-103.

Reichenbach, H. (1940). On the justification of induction. The Journal of Philosophy, 37(4), 97-103.

Richardson, A. W., \& Uebel, T. E. (2007). The Cambridge companion to logical empiricism. Cambridge: Cambridge University Press.

Rudner, R. (1953). The scientist qua scientist makes value judgments. Philosophy of Science, 20(1), 1-6.

Scharff, R. C., \& Dusek, V. (Eds.). (2003). Philosophy of technology: The technological condition. Oxford: Blackwell.

Soler, L., Zwart, S., Lynch, M., \& Israel-Jost, V. (Eds.). (2014). Science after the practice turn in the philosophy, history, and social studies of science. London: Routledge.

Sellars, W. S. (1962). Philosophy and the scientific image of man. In R. Colodny (Ed.), Frontiers of science and philosophy. Pittsburgh: University of Pittsburgh Press.

Sismondo, S. (2017). Post-truth? Social Studies of Science, 47(1), 3-6.

Wagenknecht, S., Nersessian, N. J., \& Andersen, H. (2015). Empirical philosophy of science: Introducing qualitative methods into philosophy of science. Heidelberg: Springer.

Wilson, E. O. (1999). Consilience. The unity of knowledge. New York: Random House/Vintage Books.

Wilholt, T. (2009). Bias and values in scientific research. Studies in History and Philosophy of Science Part A, 40(1), 92-101. 